\title{
Efeito do Manejo Sobre a Produção e Composição Química de Perfilhos do Capim- Colonião (Panicum maximum Jacq.)
}

\author{
Jane Maria Bertocco Ezequiel' ${ }^{1}$, Vanildo Favoretto ${ }^{2}$
}

\begin{abstract}
RESUMO - O experimento foi conduzido com o objetivo de verificar os efeitos das frequiências de corte de 28,35 e 42 dias, obtidas em dezembro, janeiro e fevereiro, cortadas rente a $15 \mathrm{~cm}$ e a $30 \mathrm{~cm}$ do solo, sobre a produção e composição química de perfilhos do capim-colonião. A área experimental foi adubada na semeadura e por ocasião dos cortes de uniformização. Verificouse que a produção de MS foi o principal fator da produção de nutrientes por área. Os teores de PB dos perfilhos apresentaram comportamento não-linear com o avanço da idade e diminuíram sensivelmente a baixas alturas e altas freqüências de corte. Os teores de FDA dos perfilhos variaram pouco entre as idades de 28 e 42 dias. Concluiu-se que o melhor manejo do capim-colonião seria o corte a cada 42 dias e a $15 \mathrm{~cm}$ do solo.
\end{abstract}

Palavras-chave: altura de corte, capim-colonião, épocas do ano, freqüência de corte, perfilhos, proteína

\section{Effect of Management on the Chemical Composition and Tillers Production of Colonião Grass (Panicum maximum Jacq.)}

\begin{abstract}
The effects of cutting frequency of 28, 35 and 42 days, performed in December, January and February at $0 \mathrm{~cm}$, $15 \mathrm{~cm}$ and $30 \mathrm{~cm}$ from the ground on the chemical composition and tiller production of Panicum maximum Jacq were assayed. The experimental area was fertilized during the sowing, at uniform cuttings. Dry matter yield was the main factor affecting the nutrients production by area. The crude protein content of tillers showed no linear response to the cutting interval and sensitively decrease at low cutting height and high cutting frequency. The ADF concentrations of tillers exhibited small variation within the interval of growth period studied of 28 to 42 days. The best management for Panicum maximum could be at 42 days cutting frequency at $15 \mathrm{~cm}$ from the ground.
\end{abstract}

Key Words: cutting height, cutting frequency, Panicum maximum, protein, tiller, year season

\section{Introdução}

O processo de desfolhamento da pastagem é complexo e a produção animal obtida é influenciada por muitas variáveis do animal, da pastagem e do ambiente. Diferenças no desempenho de animais em pastejo de diferentes relvados de pastagens tropicais podem ser melhor compreendidas e melhorados os sistemas de manejo envolvidos, se forem realizadas medições da quantidade e da composição da forragem consumida sob essas condições de campo (STOBBS, 1975).

No processo da desfolha, partes da planta são progressivamente removidas, em vez da remoção completa de uma espécie de planta (STOBBS, 1973). Quando o gado pasteja, as folhas superiores são as primeiras a serem consumidas, seguidas das folhas próximas ao caule e, finalmente, se o gado é forçado por racionamento estrito, dos caules praticamente sem folhas.

A taxa de ingestão da forragem e o tempo de pastejo são componentes essenciais dos modelos de simulação de agroecossistemas complexos e as pesquisas sobre o assunto são difíceis e demoradas. Entre as limitações dos modelos existentes de sistemas de pastejo, destacase a estimativa correta da disponibilidade de forragem e da intensidade da relação planta-animal, que regulam os processos básicos de ingestão, particularmente aqueles influenciados pelas propriedades físicas do relvado (FORBES e HODGSON, 1985).

STOBBS (1975) considerou necessários estudos tridimensionais do relvado para um completo entendimento do processo de desfoliamento, que envolvem as medidas: 1. estrutura horizontal, envolvendo produção por unidade de área e distribuição espacial das plantas; 2. arranjo vertical das espécies e partes da planta, envolvendo variações na produção e densidade da relva em cada camada vertical dentro do relvado.

Existem poucas informações sobre a distribuição vertical da forragem em stands de pastagens tropi-

\footnotetext{
1 Professor Assistente Doutor do Departamento de Zootecnia da FCAV - UNESP - Jaboticabal - SP. E.mail: janembe@fcav.unesp.br 2 Professor Titular do Departamento de Zootecnia da FCAV - UNESP - Jaboticabal - SP. E.mail: vanildo@fcav.unesp.br
} 
cais e, menos ainda, a produção de perfilhos dentro dessa distribuição vertical. WILSON (1973) realizou estudos acerca da influência do ambiente aéreo sobre a composição química e a digestibilidade da forrageira de Panicum maximum e concluiu que, ainda em uma mesma idade, folhas formadas mais tarde tendem a ser menos digestíveis.

Considerando essas observações, a presente pesquisa foi conduzida com os objetivos de comparar a produção de matéria seca (MS), proteína ( $\mathrm{PB})$ e fibra em detergente ácido (FDA) de plantas de capimcolonião obtidas em três níveis de corte, em três épocas de crescimento e em três freqüências de corte, e também analisar os teores eas produções de MS, PB e FDA em perfilhos colhidos semanalmente.

\section{Material e Métodos}

\section{Instalação do ensaio}

Esta pesquisa foi desenvolvida na área experimental da Faculdade de Ciências Agrárias e Veterinárias de Jaboticabal, durante os meses de setembro a março. O solo da área experimental corresponde a um Latossolo Roxo, segundo a COMISSÃO DE
SOLOS (1960), e pertence à série Jaboticabal (ALOISE e DEMATTE, 1974). A análise do solo apresentou os resultados: P resina $17 \mu \mathrm{g} / \mathrm{cm}^{3}, 3,7 \% \mathrm{MO}$, $\mathrm{pH} 4,9\left(\mathrm{em} \mathrm{CaCl}_{2}\right)$, saturação de bases $48 \%$, capacidade de troca de íons 10,05 meq/100 $\mathrm{cm}^{3}$ e 0,$55 ; 3,4 ; 0,8$; 5,2; e 4,85 meq/100 $\mathrm{cm}^{3}$ de $\mathrm{K}, \mathrm{Ca}, \mathrm{Mg}, \mathrm{H}+\mathrm{AL}$ e $\mathrm{S}$, respectivamente. A partir destes resultados, calculou-se a adubação necessária, sendo aplicados $120 \mathrm{~kg} / \mathrm{ha}$ de $\mathrm{P}_{2} \mathrm{O}_{5}$, por ocasião da semeadura, e $90 \mathrm{~kg} / \mathrm{ha}$ de $\mathrm{N}$ mais $60 \mathrm{~kg} / \mathrm{ha}$ de $\mathrm{K}_{2} \mathrm{O}$, aplicados parceladamente a cada corte de uniformização, utilizando-se superfosfato simples, sulfato de amônio e cloreto de potássio.

A semeadura foi realizada por intermédio de uma semeadeira-adubadeira de tração animal, em linhas espaçadas de $0,25 \mathrm{~m}$, no dia 27 de setembro, utilizando-se $5,6 \mathrm{~kg}$ de sementes por hectare, com 17,7\% de valor cultural. Para facilitar a regulagem da semeadeira, as sementes foram misturadas com o superfosfato simples.

\section{Dados climáticos}

Os dados de precipitação pluvial, temperatura e umidade relativa, registrados no decorrer do ensaio, foram obtidos no posto meteorológico de Jaboticabal, distante $300 \mathrm{~m}$ do local do experimento, e encontram-se na Tabela 1.

Tabela 1 - Temperaturas, precipitação e umidades relativas médias, por decêndios, registradas no decorrer do experimento

Table 1 - Temperature, rainfall and average relative humidity, each 10 days, recorded during the experimental phase

\begin{tabular}{|c|c|c|c|c|c|c|}
\hline \multirow[b]{2}{*}{$\begin{array}{l}\text { Mês } \\
\text { Month }\end{array}$} & \multirow[b]{2}{*}{$\begin{array}{l}\text { Decênios } \\
\text { Ten days }\end{array}$} & \multicolumn{3}{|c|}{$\begin{array}{c}\text { Temperatura }\left({ }^{\circ} \mathrm{C}\right) \\
\text { Temperature }\end{array}$} & \multirow[b]{2}{*}{$\begin{array}{l}\mathrm{UR} \% \\
U \%\end{array}$} & \multirow[b]{2}{*}{$\begin{array}{l}\mathrm{PPt}^{1} \\
\mathrm{PPt}^{1}\end{array}$} \\
\hline & & $\begin{array}{r}\text { Máxima } \\
\text { Maximum }\end{array}$ & $\begin{array}{l}\text { Mínima } \\
\text { Minimum }\end{array}$ & $\begin{array}{l}\text { Média } \\
\text { Average }\end{array}$ & & \\
\hline Setembro & 3 & 34,6 & 21,3 & 27,9 & 41,3 & 0,0 \\
\hline September & & 28,9 & 21,1 & 21,1 & 55,7 & 12,1 \\
\hline $\begin{array}{l}\text { Outubro } \\
\text { October }\end{array}$ & $\begin{array}{l}1 \\
2 \\
3\end{array}$ & $\begin{array}{l}31,5 \\
30,9 \\
28,3\end{array}$ & $\begin{array}{l}18,4 \\
19,6 \\
16,0\end{array}$ & $\begin{array}{l}19,9 \\
25,2 \\
22,2\end{array}$ & $\begin{array}{l}66,1 \\
80,0 \\
67,5\end{array}$ & $\begin{array}{r}53,0 \\
115,5 \\
15,2\end{array}$ \\
\hline $\begin{array}{l}\text { Novembro } \\
\text { November }\end{array}$ & $\begin{array}{l}1 \\
2 \\
3\end{array}$ & $\begin{array}{l}31,9 \\
29,8 \\
31,3\end{array}$ & $\begin{array}{l}19,1 \\
17,7 \\
18,1\end{array}$ & $\begin{array}{l}25,5 \\
23,8 \\
24,6\end{array}$ & $\begin{array}{l}63,2 \\
66,6 \\
62,5\end{array}$ & $\begin{array}{l}54,6 \\
60,1 \\
34,3\end{array}$ \\
\hline $\begin{array}{l}\text { Dezembro } \\
\text { December }\end{array}$ & $\begin{array}{l}1 \\
2 \\
3\end{array}$ & $\begin{array}{l}31,1 \\
34,7 \\
26,9\end{array}$ & $\begin{array}{l}20,6 \\
22,3 \\
19,7\end{array}$ & $\begin{array}{l}25,8 \\
27,0 \\
23,3\end{array}$ & $\begin{array}{l}69,6 \\
93,2 \\
87,6\end{array}$ & $\begin{array}{r}26,2 \\
125,8 \\
161,3\end{array}$ \\
\hline $\begin{array}{l}\text { Janeiro } \\
\text { January }\end{array}$ & $\begin{array}{l}1 \\
2 \\
3\end{array}$ & $\begin{array}{l}29,1 \\
31,7 \\
29,1\end{array}$ & $\begin{array}{l}17,5 \\
18,4 \\
22,9\end{array}$ & $\begin{array}{l}23,3 \\
25,0 \\
26,0\end{array}$ & $\begin{array}{l}83,6 \\
80,7 \\
83,2\end{array}$ & $\begin{array}{r}117,7 \\
19,9 \\
251,0\end{array}$ \\
\hline $\begin{array}{l}\text { Fevereiro } \\
\text { February }\end{array}$ & $\begin{array}{l}1 \\
2 \\
3\end{array}$ & $\begin{array}{l}30,3 \\
31,5\end{array}$ & $\begin{array}{l}26,1 \\
20,1\end{array}$ & $\begin{array}{l}28,2 \\
25,8\end{array}$ & $\begin{array}{l}83,1 \\
77,0\end{array}$ & $\begin{array}{l}64,6 \\
18,4\end{array}$ \\
\hline $\begin{array}{l}\text { Março } \\
\text { March }\end{array}$ & 1 & 31,1 & 19,0 & 25,0 & 79,9 & 40,4 \\
\hline
\end{tabular}

${ }^{1}$ Precipitação pluvial (Rainfall). 
1598 Rev. bras. zootec.

\section{Freqüência de corte}

O corte de uniformização inicial ocorreu no dia 04 de novembro, a $11 \mathrm{~cm}$ do solo. Estudaram-se três frequiências de corte: $28\left(\mathrm{~F}_{1}\right), 35\left(\mathrm{~F} 2_{2}\right)$ e 42 dias $\left(\mathrm{F}_{3}\right)$, contados a partir dos cortes de uniformização. Terminada a colheita de dezembro, a área colhida não era mais utilizada, sendo preparada nova área, por meio de novos cortes de uniformização, que ocorreram nos dias 16 de dezembro e 27 de janeiro, respectivamente. Épocas de corte

Estudaram-se três épocas de corte, correspondendo a dezembro $\left(\mathrm{E}_{1}\right)$, com colheitas nos dias 02, 09 e 15 de dezembro; a janeiro $\left(\mathrm{E}_{2}\right)$, com colheitas nos dias 13, 20 e 27 de janeiro e a fevereiro/ março $\left(E_{3}\right)$, com colheitas nos dias 24 de fevereiro, 03 e 10 de março, que correspondiam às freqüências de corte estudadas.

\section{Altura de corte}

O material vegetativo foi cortado, para cada frequiência, rente ao solo ( intensidade de corte B), a 15 ( intensidade de corte $\mathrm{M}$ ) e $30 \mathrm{~cm}$ do solo (intensidade de corte A), com auxílio de uma régua de corte, perfilho por perfilho, correspondendo às intensidades baixa, média e alta, respectivamente.

\section{Marcação dos perfilhos}

No dia seguinte aos cortes de uniformização, foi adubada a área experimental e marcados os perfilhos existentes. Este procedimento se repetiu semanalmente até completar as idades 28, 35 e/ou 42 dias de crescimento. Os perfilhos foram marcados com anéis coloridos de borracha, de cores diferentes, correspondendo cada cor a uma idade do perfilho. A cada sete dias, os perfilhos emergentes (durante a semana) foram identificados com colar plástico colorido, de maneira que cada semana correspondesse a uma cor. Dessa forma, aos 42 dias os perfilhos nãoidentificados com colares teriam uma semana de crescimento; aqueles identificados com a cor laranja, duas semanas; com a cor vermelha, três semanas; com a cor branca, quatro semanas, e assim por diante. Assim, na frequiência de corte $\mathrm{F}_{1}$, havia anéis de três cores (correspondendo às 4 semanas de crescimento); na $\mathrm{F}_{2}$, quatro cores; e na $\mathrm{F}_{3}$, cinco cores.

\section{Área experimental}

O campo experimental ocupou uma área de $135 \mathrm{~m}^{2}$ divididos em três áreas de $18 \times 2,5 \mathrm{~m}$, que corresponderam às repetições de campo (Blocos). Dentro de cada uma dessas áreas foram demarcadas, ao acaso, três parcelas de $6 \times 2,5 \mathrm{~m}$, que corresponderam às áreas a serem amostradas nas três épocas de crescimento (parcelas). Dentro dessas parcelas foram identificadas três subparcelas de $0,5 \times 1,5 \mathrm{~m}$, que corresponderam às freqüências de corte, as quais, por sua vez, foram divididas em três outras áreas iguais $(0,6 \times 0,5 \mathrm{~m})$, que foram destinadas às colheitas de material vegetativo correspondente às três alturas de corte (B, M e A). O modelo a seguir ilustra a disposição das parcelas e subparcelas (um bloco) no campo agrostológico.

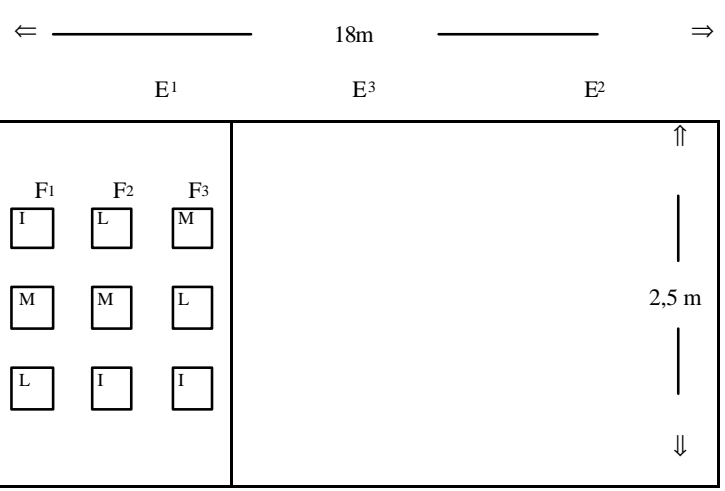

\section{Processamento das amostras}

As amostras recém-colhidas foram enviadas ao laboratório, onde se realizou a separação do material vegetal em caule, folha e material morto, por idade do perfilho e por altura de corte. Em seguida, foram pesadas, correspondendo ao peso verde. Depois de acondicionadas em sacos de papel perfurados, foram levadas à estufa com circulação e renovação de ar a $60^{\circ} \mathrm{C}$ por 72-98 horas. Após 13-14 horas de exposição ao ambiente, as amostras foram moídas em moinho Willey com $1 \mathrm{~mm}$ de diâmetro de malha da peneira.

\section{Análises laboratoriais}

Foram determinados os teores de MS, N (SILVA, 1998) e FDA (GOERING e VAN SOEST,1970). A $\mathrm{PB}$ foi estimada como PB\% $=\mathrm{N} \% \times$ 6,25.

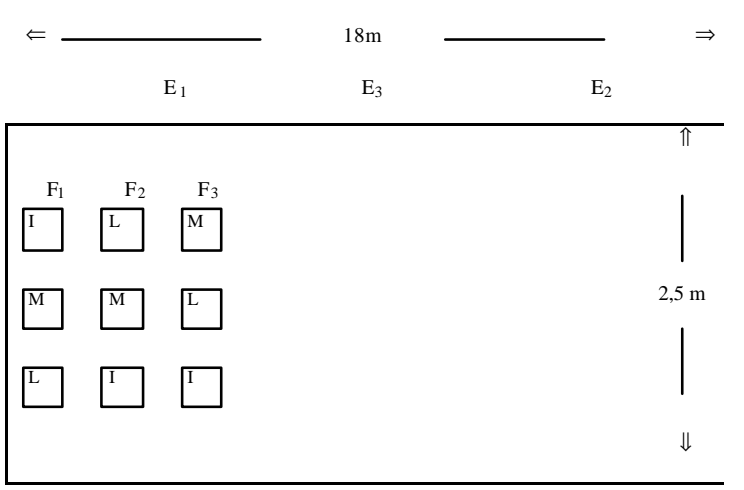


Análises estatísticas

As produções de MS, PB e FDA foram analisadas por intermédio do programa computacional SAS, segundo o delineamento experimental de blocos ao acaso, com os tratamentos arranjados em parcelas subdivididas, conforme o modelo:

$$
\begin{aligned}
& \mathrm{Y}_{\mathrm{ijkl}}=\mu+\mathrm{A}_{\mathrm{i}}+\mathrm{Bl}+\not \subset_{\mathrm{a}}+\mathrm{D}_{\mathrm{j}}+\mathrm{AD}_{\mathrm{ij}}+\not \subset_{\mathrm{b}}+\mathrm{G}_{\mathrm{k}}+ \\
& \mathrm{AG}_{\mathrm{ik}}+\mathrm{DG}_{\mathrm{jk}}+\mathrm{ADG}_{\mathrm{ijk}}+\not \subset \mathrm{c}
\end{aligned}
$$

em que $Y_{i j k l}$ é a observação 1 para a época do ano i, na frequiência de corte $\mathrm{j}$ e altura de corte $\mathrm{k}$; $\mathrm{A}_{\mathrm{i}}$, o efeito da época de corte $\mathrm{i}$; $\mathrm{B}_{1}$, o efeito de blocos (três); $\not \subset$ a oerro da parcela; $D_{j}$, o efeito da freqüência de corte $\mathrm{j} ; \mathrm{AD}_{\mathrm{ij}}$, o efeito da interação entre época $\mathrm{i}$ e freqüência de corte $\mathrm{j} ; \not \subset_{\mathrm{b}}$, o efeito do erro da subparcela; $\mathrm{G}_{\mathrm{k}}$, o efeito da altura de corte $\mathrm{k} ; \mathrm{AG}_{\mathrm{ik}}$, a interação entre a época $\mathrm{i}$ e a altura de corte $\mathrm{k} ; \mathrm{DG}_{\mathrm{jk}}$, a interação entre a freqüência j e a altura de corte $\mathrm{k} ; \mathrm{ADG}_{\mathrm{ijk}}$, o efeito da interação entre época de corte $i$, a frequiência de corte $\mathrm{j}$ e a altura de corte $\mathrm{k}$; e $\not \subset_{\mathrm{c}}$, o efeito do erro da subsubparcela.

Não foi possível efetuar a análise estatística de caule, por existirem muitas parcelas sem esse tipo de material vegetal. Assim, os dados de produção cumulativa de MS por idade semanal dos perfilhos foram dispostos em gráficos para visualização.

Tabela 2 - Produção de matéria seca/ha $(\mathrm{kg})$ em função de freqüência, época e altura de corte

Table 2 - Dry matter production/ha $(\mathrm{kg})$ in function of cutting frequency, cutting time and cutting height

\begin{tabular}{lc}
\hline $\begin{array}{l}\text { Freqüência de corte (dias) } \\
\text { Cutting frequency (days) }\end{array}$ & $\begin{array}{c}\text { Produção de matéria } \\
\text { seca/ha }(\mathrm{kg})\end{array}$ \\
\hline 28 & Dry matter production/ha \\
\hline 35 & $1650,1^{\mathrm{ab} 1}$ \\
42 & $1625,8^{\mathrm{b}}$ \\
$2126,3^{\mathrm{a}}$
\end{tabular}

\begin{tabular}{lccc}
\hline & \multicolumn{3}{c}{$\begin{array}{c}\text { Altura de corte }(\mathrm{cm}) \\
\text { Cutting height }\end{array}$} \\
\cline { 2 - 4 } $\begin{array}{l}\text { Época de corte } \\
\text { Cutting time }\end{array}$ & 0 & 15 & 30 \\
\hline $\begin{array}{l}\text { Dezembro } \\
\text { December }\end{array}$ & $3124,6^{\mathrm{Ab}}$ & $1410,9^{\mathrm{Bb}}$ & $309,7^{\mathrm{Cb}}$ \\
$\begin{array}{l}\text { Janeiro } \\
\text { January }\end{array}$ & $3656,2^{\mathrm{Aa}}$ & $2484,6^{\mathrm{Ba}}$ & $1086,0^{\mathrm{Ca}}$ \\
$\begin{array}{l}\text { Fevereiro/março } \\
\text { February/March }\end{array}$ & $2421,5^{\mathrm{Ac}}$ & $1209,9^{\mathrm{Bb}}$ & $503,1^{\mathrm{Cb}}$ \\
\hline
\end{tabular}

1 Médias seguidas das mesmas letras, maiúsculas nas linhas e minúsculas nas colunas, não diferem pelo teste Tukey $(P>0,05)$.

1 Values followed by the same letters, capital in the row and small in the columns, do not differ by Tukey test (P>.05).

\section{Resultados e Discussão}

A produção de MS por hectare, obtida durante o período experimental, encontra-se na Tabela 2. Estes valores podem ser considerados relativamente baixos, haja vista os resultados obtidos por COSTA (1990), em condições semelhantes e com a mesma gramínea. Convém salientar que, nesta pesquisa, foram obtidas pequenas produções, quando se consideraram os cortes à intensidade $\mathrm{A}(30 \mathrm{~cm}$ do solo), em especial para as épocas de dezembro e fevereiro/março (309,7 e $503,1 \mathrm{~kg} \mathrm{MS} / \mathrm{ha})$. O relvado apresentou-se mais espalhado do que ereto, talvez devido ao fato de os cortes de uniformização terem sido efetuados a $11 \mathrm{~cm}$ do solo, o que pode então ter propiciado desenvolvimento da planta com maior intensidade abaixo do nível de corte A, $30 \mathrm{~cm}$ (desenvolvimento de gemas axilares, crescimento de raízes, desenvolvimento de perfilhos secundários etc). A produção acentuada que ocorreu em janeiro, em relação às demais épocas, pode ser atribuída à uniformidade na precipitação pluviométrica, que ocorreu desde a época do corte de uniformização até o corte correspondente à $\mathrm{F}_{2}$ dessa época. FAVORETTO (1981) e FAVORETTO et al. (1987) obtiveram maiores rendimentos forrageiros quando o

Tabela 3 - Produção de matéria seca foliar/ha (kg), em função de época, freqüência e altura de corte

Table 3 - Leafdrymatterproduction/ha $(\mathrm{kg})$, in function of cutting time, cutting frequency and cutting height

Época de corte Produção de matéria

Cutting time seca foliar $/ \mathrm{ha}(\mathrm{kg})$

Leaf dry matter production/ha

Dezembro

$1178,8^{\text {b1 }}$

December

Janeiro $1898,4^{\mathrm{a}}$

January

Fevereiro/março $\quad 1094,1^{\mathrm{b}}$

February/March

Frequiência de corte (dias)

Cutting frequency (days)

\begin{tabular}{ll}
\hline 28 & $1240,4^{\mathrm{b}}$ \\
35 & $1295,7^{\mathrm{ab}}$ \\
42 & $1635,3^{\mathrm{a}}$ \\
\hline
\end{tabular}

Altura de corte $(\mathrm{cm})$

Cutting height

\begin{tabular}{lr}
\hline 0 & $1906,5^{\mathrm{a}}$ \\
15 & $1637,9^{\mathrm{b}}$ \\
30 & $626,9^{\mathrm{c}}$ \\
\hline
\end{tabular}

1 Para cada fator, médias seguidas das mesmas letras não diferem pelo teste Tukey $(P>0,05)$.

1 Values followed by the same letter in the same factor do not differ by Tukey test $(P>05)$. 
1600

Rev. bras. zootec.

capim-colonião foi manejado a intervalos de 35 a 42 dias. GERDES (1999) obteve produção de MS com o capim-tanzânia aos 145 dias de crescimento de 6,04 t/ha. Na presente pesquisa, considerando-se as intensidades de corte estudadas, as frequiências 28 e 35 dias apresentaram produções de MS de 22 e $23 \%$, respectivamente, mais baixas que a frequência 42 dias. Pode-se, assim, recomendar um manejo a intervalos de 42 dias, para se obter produção de MS por hectare mais elevada.

A produção de MS foliar por hectare (Tabela 3) foi, em média, 73 a $80 \%$ da produção de MS por hectare da planta inteira nas épocas e nas freqüências estudadas. Todavia, como era de se esperar, estes valores foram da ordem de $62 \%$ para a intensidade de corte B e 96 e $99 \%$ para as intensidades $\mathrm{M}$ e A, respectivamente. Isto significou, então, que os colmos obtidos (por colmos entende-se o perfilho depois de retiradas as lâminas de folhas expostas) só tiveram expressão para a produção de MS obtida na intensi- dade de $0 \mathrm{~cm}$ (B), o que proporcionou relação folha/ colmo de aproximadamente 1,0 . Nas demais intensidades, pode-se considerar que a produção de MS obtida foi, aproximadamente, $100 \%$ constituída de folhas. A influência da época de corte foi bem acentuada na produção de MS foliar, com aquela obtida em janeiro, superior em relação às obtidas em dezembro e fevereiro/março.

Novamente, pode-se considerar que estes valores foram decorrentes das condições climáticas e pluviométricas operantes no período. Com respeito às frequiências de corte estudadas, não foram observados os mesmos efeitos das idades de corte obtidos por COSTA(1990), em seus estudos com capimcolonião. A produção de MS de folhas verdes obtidas por esse autor foram bem distintas para os cortes aos 28,35 e 42 dias de idade das plantas. Deve ser levado em conta também que, no presente ensaio, as produções foram obtidas pela média das produções encontradas em cortes a 0,15 e $30 \mathrm{~cm}$ do solo. Qualquer
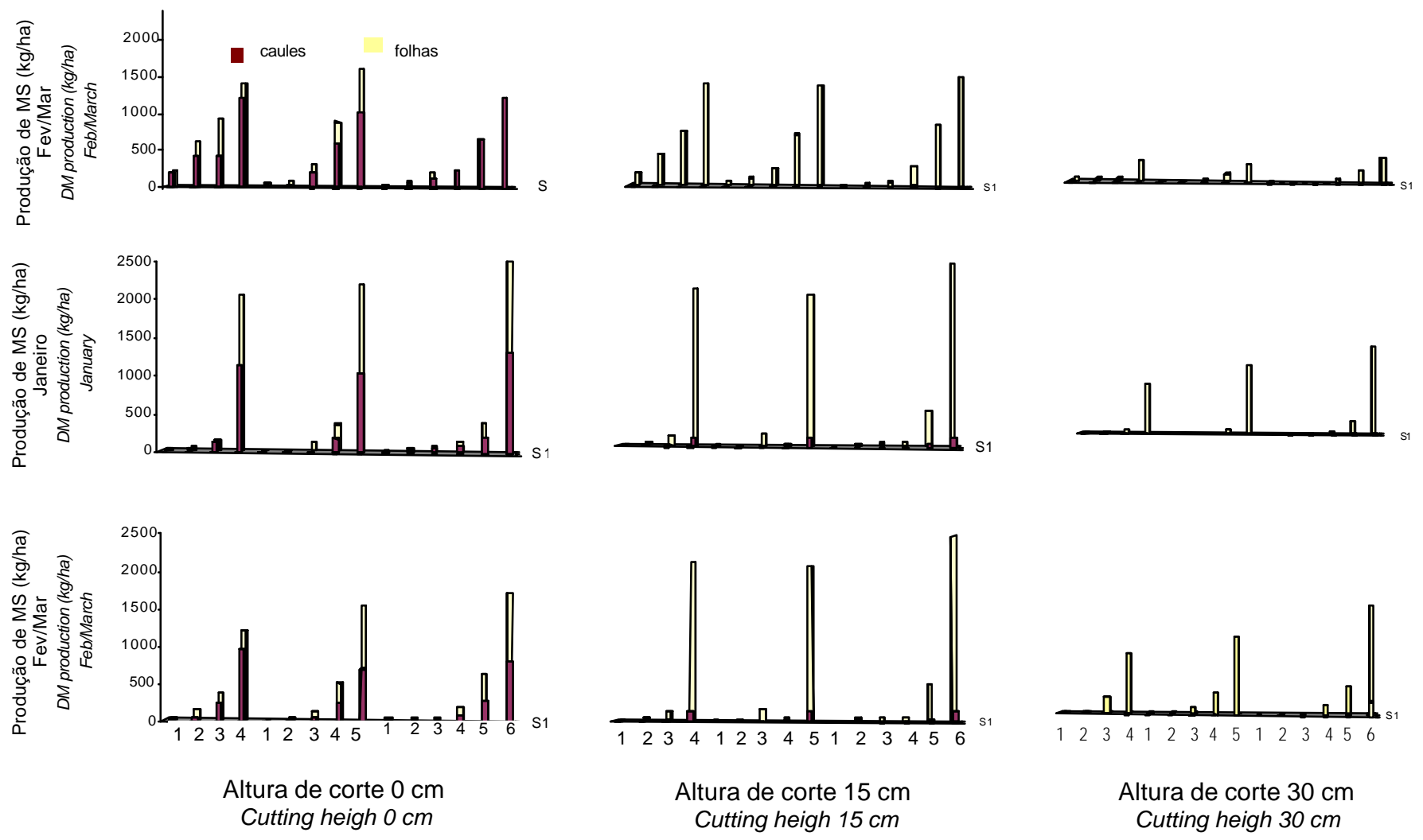

Semanas de crescimento dos perfilhos Weeks of tillers growth

Figura 1 - Produção total de matéria seca dos perfilhos, caule e folhas, nas épocas, frequências e alturas de corte. Figure 1 - Total dry matter production of steam and leaves in relation to the cutting time, frequency and height. 
variação na proporção da massa de MS produzida entre esses tratamentos pode ter afetado os resultados obtidos tanto nas épocas como nas frequiências de corte estudadas. Outra consideração a ser feita novamente seria a altura do corte de uniformização. STOBBS (1973) encontrou aumentos na produção de MS de Setaria anceps cv Kazungula até 8 semanas de idade por influência do corte de uniformização, muito baixo para a espécie. Pode-se inferir que, se na presente pesquisa o corte de uniformização fosse efetuado, por exemplo, a $20 \mathrm{~cm}$ do solo, os perfilhamentos secundário, terciário e outros seriam provavelmente menos intensos que os ocorridos, podendo levar a resultados diferentes dos obtidos presentemente. GERDES (1999) obteve produção de MS de 3,30 e 2,88 t/ha aos 35 dias de crescimento com 81,7 e $81,9 \%$ de lâminas, respectivamente.

A Figura 1 ilustra os resultados de produção acumulada de MS para as épocas, freqüências e alturas de corte estudadas e, ainda, por semana de idade dos perfilhos. Observa-se que, em dezembro, o aumento na produção acumulada de MS foi gradual, o que não ocorreu nas épocas janeiro e fevereiro/ março. Nestas, produção considerável de MS ocorreu praticamente na última semana de cada período de crescimento. Esse comportamento pode ser resposta da forrageira aos cortes de uniformização (um para dezembro, dois para janeiro e três para fev/mar). GERDES (1999) obteve produção de MS $13 \%$ inferior no outono em relação ao verão, com o capim-tanzânia, aos 35 dias de crescimento.

PEDREIRA (1975), estudando os hábitos de perfilhamento do capim-colonião, verificou que o perfilhamento foi baixo em dois períodos, nos $2 / 3$ finais de verão (fim de janeiro a meados de março) e no fim do outono. A redução do perfilhamento no final do verão foi atribuída ao sombreamento verificado na base da planta, bem como à dominância apical dos perfilhos alongados. Realmente, na presente pesquisa, a ausência de perfilhos nas primeiras semanas de crescimento foi maior em janeiro e fevereiro/março em relação a dezembro. Os cortes de dezembro e janeiro foram efetuados justamente nos 2/3 finais do verão relatados por aquele autor. Todavia, essa condição não afetou a produção de MS, pelo menos para o mês de janeiro, que apresentou o maior valor de produção entre as épocas de corte estudadas. GERDES (1999) obteve resultados demonstrando que o número de perfilhos por metro linear aumentou para o capim-tanzânia segundo modelo linear, com início de perfilhamento aos 14 dias, sendo de $21,27,48,71$ e 91 o número de perfilhos aos 7 , $14,21,28$ e 35 dias após o plantio, respectivamente. Levando-se em consideração então que, sob condições de pastejo, os animais podem obter alimento em qualquer desses estratos verticais (STOBBS, 1973), a freqüência de corte recomendada para se obter maior produção de MS foliar por hectare seria $\mathrm{a} \mathrm{F}_{3}, 42$ dias.

No tocante aos teores de PB dos perfilhos a diferentes idades, alturas de corte e épocas (Tabelas 4, 5 e 6), é interessante assinalar que, na época de maior produção de MS (janeiro), o teor médio de PB das folhas foi de 11,4\% e dos colmos, 5,9\%. Em dezembro e fevereiro/março, esses valores foram da ordem de 10,5 e 5,4 e 14,6 e 6,4\%, respectivamente. Observa-se, então, não haver correspondência entre a produção de MS e o teor de PB do capim-colonião, nas diferentes épocas de crescimento. Todavia, a produção de proteína bruta por hectare (Tabelas 7 e 8) tende a acompanhar a produção de MS por hectare. Dessa forma, o parâmetro MS parece ser mais influente na tomada de decisão do manejo mais adequado dessa gramínea forrageira. Além disso, melhor expressão seria a produção de MS foliar, conforme também concluíram LAREDO E MINSON(1973).

Os teores de PB dos perfilhos aparentemente foram mais influenciados pela altura e frequiência de corte do que pela época de corte (Tabelas 4,5 e 6). Houve grande aumento nos teores de PB, com o aumento das alturas de corte em todas as freqüências de corte estudadas. De forma inversa, foi substancial a redução dos teores de $\mathrm{PB}$ tanto de caules quanto de folhas, com o aumento nos espaçamentos de corte, dentro de cada altura de corte. Assim, por exemplo, na intensidade de corte $0 \mathrm{~cm}$, os valores médios de PB para os colmos foram de 7,$0 ; 5,7$; e $5,3 \%$ para as freqüências de corte 28, 35 e 42 dias, respectivamente, e para as folhas, de 13,6; 10,5; e 9,6\%. Estes resultados concordam plenamente com os obtidos por STOBBS (1975).

O comportamento não-linear do declínio do teor de PB, com a idade dos perfilhos e mesmo com a intensidade de corte, foi bem diferente daquele obtido por WILSON (1976a). Este pesquisador verificou, ainda, declínio na porcentagem de $\mathrm{N}$ mais rápido para folhas de nível de inserção mais baixo.Considerando-se, na presente pesquisa, que as folhas na intensidade de corte $30 \mathrm{~cm}$ apresentaram maior proporção de folhas de nível mais alto de inserção que as obtidas na intensidade de corte $0 \mathrm{~cm}$, estas deveriam, então, diminuir os teores de $\mathrm{PB}$ mais rapidamente que aquelas. 


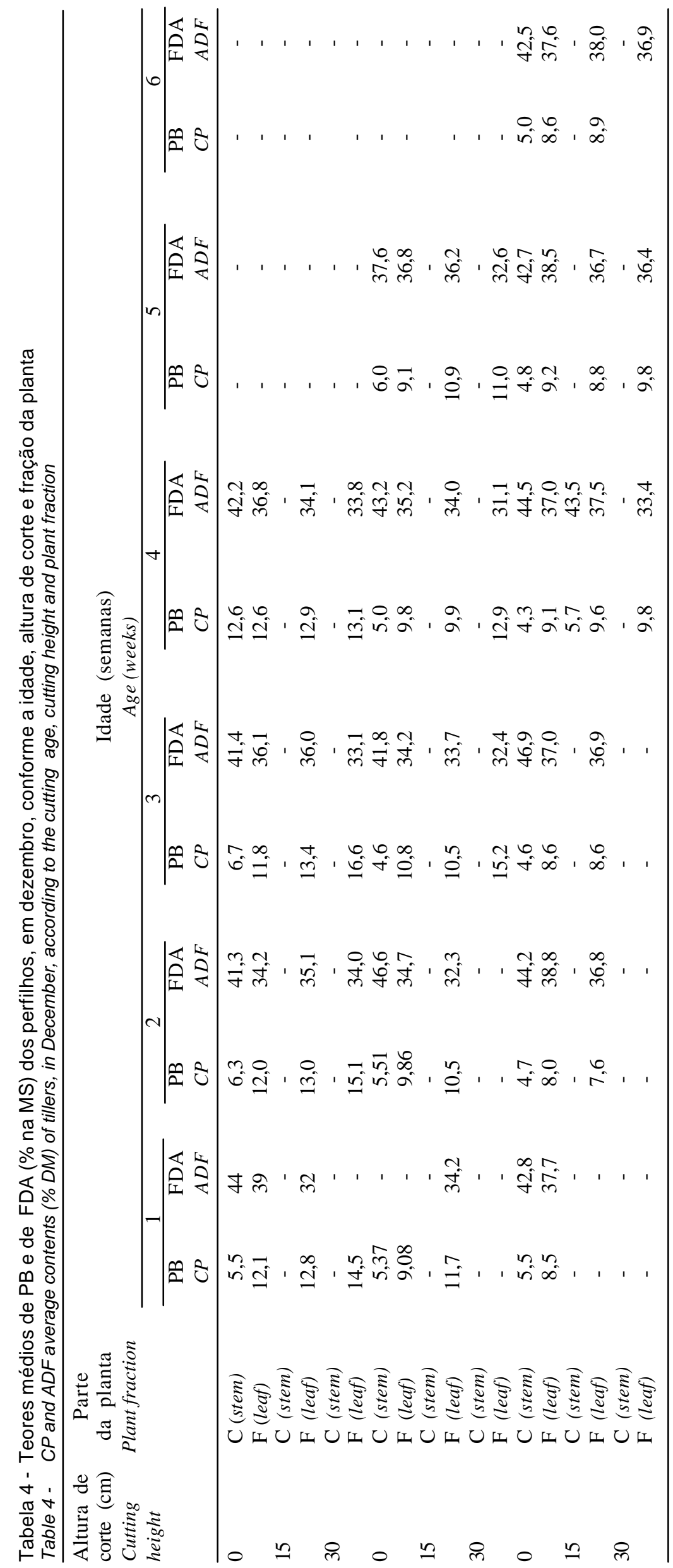




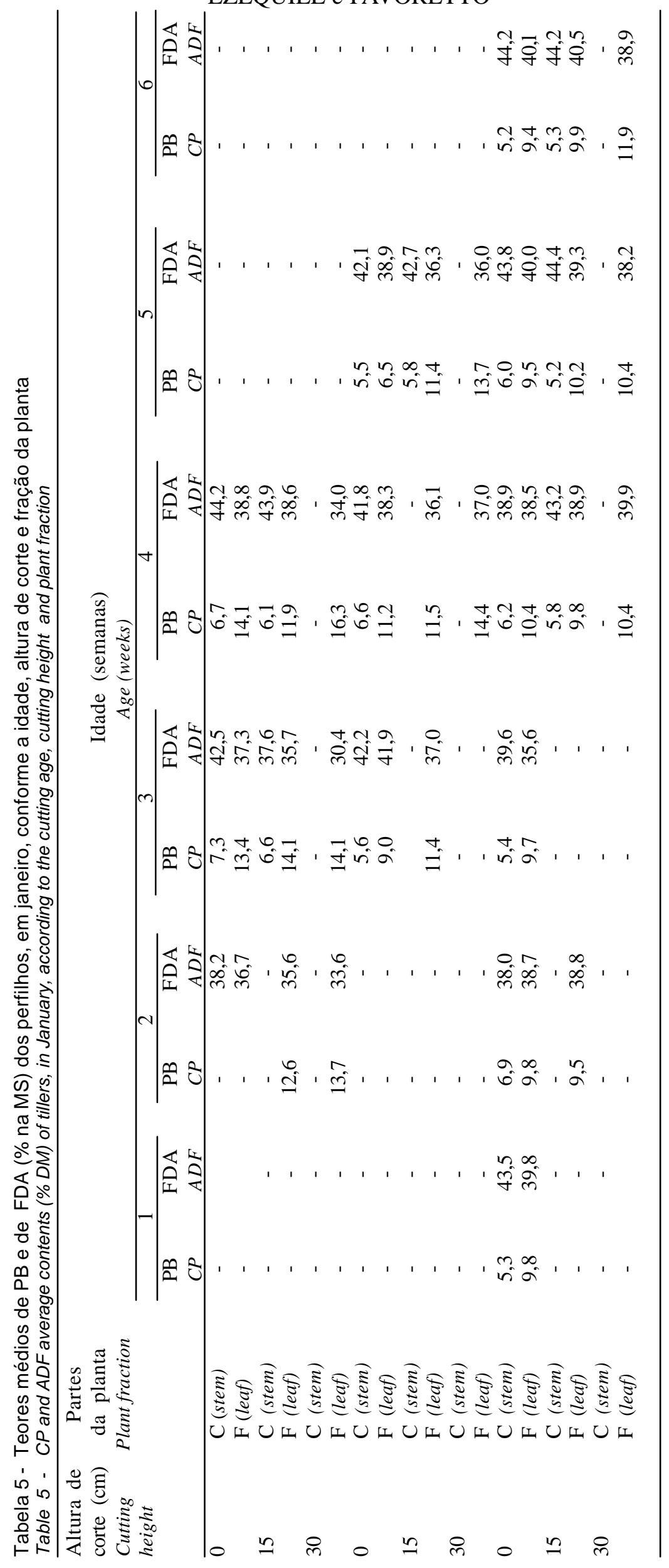


1604 Rev. bras. zootec.

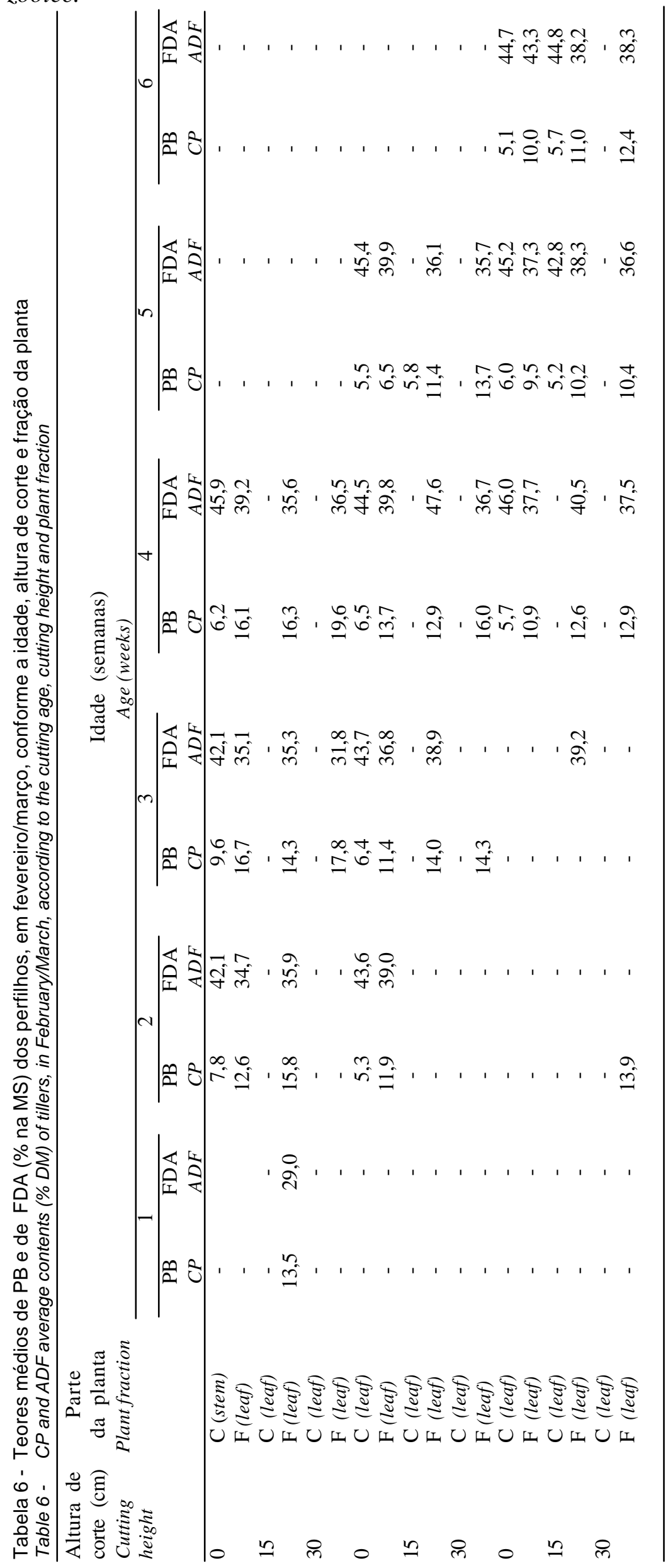


Tabela 7 - Produção de PB da planta inteira $(\mathrm{kg} / \mathrm{ha})$, em função da época, freqüência e altura de corte

Table 7 - Crude protein production of the whole plant ( $\mathrm{kg} / \mathrm{ha}$ ), in function of cutting time, cutting frequency and cutting height

Época de corte Produção de PB (kg/ha) Cutting time Whole plant CP production

Dezembro $147,1^{\text {b1 }}$

December

Janeiro

$243,4^{\mathrm{a}}$

January

Fevereiro

$140,5^{\mathrm{b}}$

February

\begin{tabular}{|c|c|c|c|}
\hline \multirow[b]{2}{*}{$\begin{array}{l}\text { Freqüência de corte } \\
\text { Cutting frequency }\end{array}$} & \multicolumn{3}{|c|}{$\begin{array}{c}\text { Altura de corte }(\mathrm{cm}) \\
\text { Cutting height }\end{array}$} \\
\hline & 0 & 15 & 30 \\
\hline 28 & $333,4^{\mathrm{Aa}}$ & $210,6^{\mathrm{Ba}}$ & $66,4^{\mathrm{Ca}}$ \\
\hline 35 & $213,6^{\mathrm{Ab}}$ & $179,8^{\mathrm{Aa}}$ & $79,3^{\mathrm{Ba}}$ \\
\hline 42 & $248,9^{\mathrm{Ab}}$ & $180,5^{\mathrm{Ba}}$ & $80,3^{\mathrm{Ca}}$ \\
\hline
\end{tabular}

Tabela 8 - Produção de PB da folha (kg/ha)em função da altura, época e freqüência de corte

Table 8 - Leaf crude protein production in function of cutting height, cutting time and cutting frequency

\begin{tabular}{lccc}
\hline Item & \multicolumn{3}{c}{$\begin{array}{c}\text { Altura de corte }(\mathrm{cm}) \\
\text { Cutting height }\end{array}$} \\
\cline { 2 - 4 } & 0 & 15 & 30 \\
\hline \multirow{2}{*}{$\begin{array}{c}\text { Produção de PB da folha } \\
\text { Leaf crude protein production }\end{array}$} \\
\hline
\end{tabular}

Época de corte

Cutting time

\begin{tabular}{lccc}
\hline $\begin{array}{l}\text { Dezembro } \\
\text { December }\end{array}$ & $182,8^{\mathrm{Ab} 1}$ & $158,1^{\mathrm{Ab}}$ & $36,9^{\mathrm{Bb}}$ \\
$\begin{array}{l}\text { Janeiro } \\
\text { January }\end{array}$ & $236,6^{\mathrm{Aa}}$ & $267,0^{\mathrm{Aa}}$ & $145,6^{\mathrm{Ba}}$ \\
$\begin{array}{l}\text { Fevereiro } \\
\text { February }\end{array}$ & $196,4^{\mathrm{Ab}}$ & $136,4^{\mathrm{Bb}}$ & $43,2^{\mathrm{Cb}}$ \\
\hline Freqüência de corte (dias) & & & \\
Cutting frequency (days) & & & \\
\hline 28 & $255,4^{\mathrm{Aa}}$ & $208,0^{\mathrm{Ba}}$ & $66,4^{\mathrm{Ca}}$ \\
35 & $162,0^{\mathrm{Ab}}$ & $177,1^{\mathrm{Aa}}$ & $79,3^{\mathrm{Ba}}$ \\
42 & $198,4^{\mathrm{Ab}}$ & $176,4^{\mathrm{Aa}}$ & $80,0^{\mathrm{Ba}}$ \\
\hline
\end{tabular}

${ }^{1}$ Médias seguidas das mesmas letras, maiúsculas nas linhas $e$ minúsculas nas colunas, não diferem pelo teste Tukey $(P>0,05)$.

1 Values followed by the same letter, capital in the row and small in the columns do not differ by Tukey test (P>.05).
Aparentemente, ocorreu tendência inversa. Os resultados de GERDES (1999), obtidos para o capimtanzânia aos 35 dias de crescimento foram de 15,5 e $8,0 \%$ de PB para folhas e caules, respectivamente, na época do verão, valores semelhantes aos obtidos nesta pesquisa para 4 e 5 semanas de crescimento do capim-colonião.

Os trabalhos de WILSON (1976a), WILSON (1976b), WILSON e NG (1975), WILSON (1973) e WILSON et al. (1989) mostraram resultados comprobatórios da existência de diferenças na anatomia tanto de folhas quanto de bainha que se refletem nos teores de $\mathrm{N}$ e de fibra em detergente neutro com o tipo de perfilho e o nível de inserção da folha no mesmo. Nesta pesquisa, não foi possível detectar de forma marcante a influência da altura de corte das plantas em seus teores de FDA (Tabela 9). Houve leve disposição em reduzir o teor dessa fração nos níveis mais altos de corte das plantas, mas essa conduta não foi homogênea nos distintos tratamentos para todas as idades dos perfilhos. COSTA (1990) verificou teores de fibra bruta menores na época de corte, que apresentou menor produção de folhas verdes. Nesta pesquisa, observou-se esse comportamento. A média dos teores de FDA foi de 37,6\% em janeiro, em que se obteve maior produção de MS foliar, e, em média, de $36,3 \%$ para dezembro e fevereiro/março, nos quais foram obtidas menores produções de MS das folhas.

Todavia, assim como ocorreu para a produção de $\mathrm{PB}$, a produção de FDA por hectare (Tabela 9) diminuiu sensivelmente com o aumento na altura de corte das plantas, o que, mais uma vez, parece ser decorrente da menor produção de MS do que propriamente diminuições nos teores de FDA das plantas.

$\mathrm{O}$ caule contribuiu pouco para a produção de FDA por hectare, correspondendo a $23,4 \%$ da produção da planta inteira. $\mathrm{Na}$ intensidade $0 \mathrm{~cm}$, essa participação foi de 38\%, mas nas intensidades 15 e $30 \mathrm{~cm}$ foi de, aproximadamente, 0 a $2 \%$.

A influência da altura de corte na produção de FDA foliar por hectare (Tabela 9) foi marcante, em especial entre as intensidades de corte de 15 e $30 \mathrm{~cm}$, nas quais a produção a $30 \mathrm{~cm}$ correspondeu a $37 \%$ da produção obtida no corte a $15 \mathrm{~cm}$ do solo. Provavelmente, esse comportamento reflete o hábito de crescimento do capim-colonião. Próximo ao solo, a massa produzida possui maior proporção de material de 
1606 Rev. bras. zootec.

Tabela 9 - Produção de FDA da folha e da planta inteira ( $\mathrm{kg} / \mathrm{ha}$ ), em função da época, freqüência e altura de corte

Table 9 - Leaf and whole plant ADF production in function of cutting time, cutting frequency and cutting height

\begin{tabular}{lcc}
\hline Item & $\begin{array}{c}\text { Produção de FDA } \\
\text { da folha }(\mathrm{kg} / \mathrm{ha}) \\
\text { Leaf } A D F \\
\text { production }\end{array}$ & $\begin{array}{c}\text { Produção de FDA } \\
\text { danta inteira }(\mathrm{kg} / \mathrm{ha}) \\
\text { Whole plant }\end{array}$ \\
\begin{tabular}{l} 
ADF production \\
\hline $\begin{array}{l}\text { Época de corte } \\
\text { Cutting time }\end{array}$
\end{tabular} & \\
\hline $\begin{array}{l}\text { Dezembro } \\
\text { December }\end{array}$ & $424,1^{\mathrm{b} 1}$ & $577,1^{\mathrm{b}}$ \\
$\begin{array}{l}\text { Janeiro } \\
\text { January }\end{array}$ & $729,2^{\mathrm{a}}$ & $921,4^{\mathrm{a}}$ \\
$\begin{array}{l}\text { Fevereiro } \\
\text { February }\end{array}$ & $424,6^{\mathrm{b}}$ & $548,3^{\mathrm{b}}$ \\
\hline
\end{tabular}

Frequiência de corte

(dias)

Cutting frequency

(days)

\begin{tabular}{lll}
\hline 28 & $454,5^{\mathrm{b}}$ & $630,6^{\mathrm{b}}$ \\
35 & $485,5^{\mathrm{b}}$ & $613,3^{\mathrm{b}}$ \\
42 & $637,9^{\mathrm{a}}$ & $803,5^{\mathrm{a}}$ \\
\hline
\end{tabular}

Altura de corte $(\mathrm{cm})$

Cutting height

\begin{tabular}{llr}
\hline 0 & $734,8^{\mathrm{a}}$ & $1188,2^{\mathrm{a}}$ \\
15 & $615,0^{\mathrm{b}}$ & $632,6^{\mathrm{b}}$ \\
30 & $228,0^{\mathrm{c}}$ & $226,6^{\mathrm{c}}$ \\
\hline
\end{tabular}

1 Para cada fator, médias seguidas das mesmas letras, por tratamentos, não diferem pelo teste Tukey $(\mathrm{P}>0,05)$.

1 Values followed by the same letters in the same factor, do not differ by Tukey test ( P. 05).

suporte, sabidamente constituída de tecido vascular e esclerênquima (WILSON e HACKER, 1987; WILSON e HATTERSLEY, 1989), que contribuem para o aumento dos teores de FDA das plantas.

A produção de FDA/ha refletiu mais os valores obtidos para folhas do que para caules, como ocorreu com a PB, devido à maior produção de massa foliar do que de caule, em todas as épocas de crescimento, freqüências e alturas de corte estudadas.

A influência da idade do perfilho foi praticamente a mesma na variação dos teores de FDA das folhas e dos colmos (Tabelas 4, 5 e 6). Para as idades de 1, 2, 3, 4, 5 e 6 semanas dos perfilhos, os teores médios de FDA para caules e folhas, respectivamente, foram de 40,6 e $35,5 \% ; 42,0$ e $35,9 \% ; 42,0$ e $37,6 \% ; 43,4$ e $37,2 \%$; 43,0 e 37,2\%; e 44,1 e 39,1\%. Assim, o aumento nesses teores, indistintamente para caules e folhas, foi de aproximadamente 4 unidades percentuais ( $8,6 \%$ para caule e $10,1 \%$ para folhas). Uma obser- vação interessante é que os teores de FDA dos perfilhos jovens (1, 2 ou 3 semanas de idade) foram semelhantes aos teores de FDA dos perfilhos com 4, 5 ou 6 semanas de idade obtidos em dezembro. Nas épocas janeiro e fev/mar, ocorreu aumento mais substancial nos teores dessa fração, com o decorrer da idade do perfilho, devido, provavelmente, ao crescimento mais uniforme durante o período de crescimento das plantas em dezembro, em relação a janeiro e fevereiro/março. GERDES (1999) obteve resultados de FDN para lâminas e colmos de capim-tanzânia aos 35 dias de crescimento, no verão, de 74,8 e $79,8 \%$, respectivamente, o que representa o mesmo diferencial (aproximadamente 5 unidades percentuais) obtido, nesta pesquisa, para FDA.

De maneira geral, os resultados deste experimento corroboram aqueles obtidos por KORTE et al. (1982), que consideraram a altura de pastejo e a massa de forragem residuais como fatores que definem a intensidade de desfolhamento. A qualidade da pastagem pode ser definida por suas características físicas e químicas, entre outras (RODRIGUES, 1984), que diferem em seu desenvolvimento vertical, arranjamento dos perfilhos e acessibilidade de folhas (CROWDER e CHHEDA, 1982).

\section{Conclusões}

A produção de MS por hectare, em especial a produção de MS das folhas, foi o principal determinante das produções de nutrientes por área.

A produção de MS por hectare, tanto da planta inteira como somente de folhas, sofreu influência do manejo imposto ao capim-colonião, principalmente a altura de corte.

O comportamento do teor de $\mathrm{PB}$, com o avançar da idade do perfilho, foi não linear, porém diminuiu sensivelmente a baixas alturas de corte e com o aumento nos espaçamentos de corte.

A idade do perfilho apresentou pequena influência nos teores de FDA, tanto de folhas quanto de colmos, entre 0 e 6 semanas de crescimento do capim-colonião.

A maior produção de MS por hectare aos 42 dias de crescimento, o que refletiu em maiores produções de PB por hectare, induziu à recomendação desse manejo ao capim-colonião durante os meses de verão. 


\section{Referências Bibliográficas}

ALOISI, R.R.,DEMATTE, J.L.I. 1974. Levantamento dos solos da Faculdade de Medicina Veterinária e Agronomia de Jaboticabal. Científica, 2(2):123-136.

COMISSÃO DE SOLOS. 1960. Levantamento de reconhecimento de solos do Estado de São Paulo. Rio de Janeiro. 643p (Boletim 12).

COSTA, C. Estudo da variação na estrutura da vegetação de dois cultivares de Panicum maximum Jacq. (Colonião e Tobiatã) submetidos a diferentes tipos de manejo. Jaboticabal, SP: UNESP, 1990. 96p. Tese (Doutorado em Produção Animal) - Faculdade de Ciências Agrárias e Veterinárias de Jaboticabal/Universidade Estadual Paulista, 1990.

CROWDER, L.V, CHHEDA, H.R. 1982. Tropical grassland husbandry. New York: Longman Group Limited. 562p.

FAVORETTO, V. Efeito de diferentes freqüências de corte $e$ níveis de aplicação de nitrogênio sobre a utilização de capimcolonião (Panicum maximum Jacq,) para pastejo e fenação. Jaboticabal, SP: UNESP. 1981. 80p. Tese (Livre Docência) - Faculdade de Ciências Agrárias e Veterinárias de Jaboticabal/ Universidade Estadual Paulista, 1981.

FAVORETTO, V., TONINI JR., R., REIS, R.A. et al. 1987. Efeito da altura e da freqüência de corte sobre a produção, composição bromatológica e vigor de rebrota do capimcolonião. Pesq. Agrop. Bras., 22(11-12):1279-1285.

FORBES, T.D.A., HODGSON, J. 1985. Comparative studies on the influence of sward conditions on the ingestive behaviour of cows and sheep. Grass and Forage Sci., 40(1):69-77.

GERDES, L.Algumas características agronômicas, morfológicas e de valor nutritivo dos capins Marandú, Setária e Tanzânia. Pirassununga, SP: USP, 1999. 82 p. Dissertação (Mestrado em Zootecnia) - Faculdade de Medicina Veterinária e Zootecnia/Universidade de São Paulo, 1999.

GOERING, H.K.,VAN SOEST, P. J. 1970. Forage fiber analysis (apparatus, reagents, procedures and some applications). Agricultural Research Service, United States Department of Agriculture. Washington. (Agricultural Handbook n ${ }^{\circ} 379$ ). 20p.

KORTE, C.J., WATKIN, B.R., HARRIS,W. 1982. Use of residual leaf area index and light interception as criteria for spring-grazing management of a ryegrass-dominant pasture. New Zealand J. Agric. Res., 25(1):309-319.

LAREDO, M.A., MINSON, D.J. 1973. The voluntary intake, digestibility and retention time by sheep of leaf and stem fractions of five grasses.Austr. J. Agric. Res., 24(2):875-888.

LEMPP, B. Avaliações qualitativas, químicas, biológicas e anatômicas de lâminas de Panicum maximum Jacq. cvaruana e vencedor. Jaboticabal, SP: UNESP 1997. 148p. Tese (Doutorado em Produção Animal) - Faculdade de Ciências Agrárias e Veterinárias de Jaboticabal/Universidade Estadual Paulista,1997.

PEDREIRA, J.V.S. 1975. Hábitos de perfilhamento do capimcolonião (Panicum maximum Jacq.). Bol. Ind. Anim., 32(1):111-114.

RODRIGUES, L.R.A. Morphological and physiological responses of dwarf elephantgrass (Pennisetum purpureum (L.) Schum.) to grazing management. Florida, University of Florida, 1984. 192p. Thesis (Doctor Science).University of Florida, 1984

SILVA, D.J. 1998. Análise de alimentos (métodos químicos e biológicos), Viçosa, MG: UFV. 166p.

STOBBS, T.H. 1973. The effect of plant structure on the intake of tropical pastures. II. Diferences in sward structure, nutritive value, and bite size of animals grazing Setaria anceps and Chloris gayana at various stages of growth.Austr. J. Agric. Res., 24(1):321-329.

STOBBS, T.H. 1975. Factors limiting the nutritional value of grazed tropical pastures for beef and milk production.Trop. Grassl., 9(2):141-149.

WILSON, J.R. 1973. The influence of aerial environment nitrogen supply and ontogenical changes on the chemical composition and digestibility of Panicum maximum var. trichoglume. Austr. J. Agric. Res., 24(2):543-556.

WILSON, J.R., NG, T.T. 1975. Influence of water stress on parameters associated with herbage quality of Panicummaximum var.trichoglume. Austr. J. Agric. Res., 26(1):127-136.

WILSON, J.R. 1976a. Variation of leaf characteristics with level of insertion on a grass tiller. I. Development rate, chemical composition and dry matter digestibility. Austr. J. Agric. Res., 27(1):343-354.

WILSON, J.R. 1976b. Variation of leaf charcateristics with level of insertion on a grass tiller. II. Anatomy. Austr. J. Agric. Res., 27(1):355-364.

WILSON, J.R., HACKER, J.B. 1987. Comparative digestibility and anatomy of some sympatric $\mathrm{C}_{3}$ and $\mathrm{C}_{4}$ arid zone grasses. Austr. J. Agric. Res., 38(1):282-295.

WILSON, J.R., ANDERSON, K.L., HACKER, J.B.1989. Dry matter digestibility in vitro of leaf and stem of Buffel (Cenchrus ciliaris) and related species and its relation to plant morphology and anatomy. Austr. J. Agric. Res., 40(1):281-291.

WILSON, J.R., HATTERSLEY, P.W. 1989.Anatomical characteristics and digestibility of leaves of Panicum and other grass genera with $\mathrm{C}_{4}$ photosynthetic pathway. Austr. J. Agric. Res., 40(1):125-136

Recebido em: 04/10/99

Aceito em: 29/05/00 